\title{
Deformed spinal needle causing PDPH and dry tap due to blood clot
}

\author{
This article was published in the following Dove Press journal: \\ Local and Regional Anesthesia \\ 12 June 2010 \\ Number of times this article has been viewed
}

\author{
Rakesh Garg \\ Ashwani Kumar \\ Ravindra Pandey \\ Department of Anesthesiology and \\ Intensive Care, All India Institute \\ of Medical Sciences. Ansari Nagar, \\ New Delhi-I I0029, India
}

\begin{abstract}
Postdural puncture headache (PDPH) is a significant complication of spinal anesthesia. There is considerable variability in the incidence of PDPH, which is affected by a number of factors including age, gender, pregnancy, and needle type and size. We present a case where a patient had PDPH after a spinal block with a deformed spinal needle due to calcified interspinous ligaments. We suggest, in the elderly patient with possible ligament calcification, an introducer needle should be used to achieve the spinal block and if there are multiple attempts then the needle should be checked for damage in between. Also, change in the resistance from previous tries or a gritting sensation during needle insertion should be taken seriously and the needle checked before further attempts are made.
\end{abstract}

Keywords: PDPH, damaged spinal needle tip, elderly

\section{Introduction}

Postdural puncture headache (PDPH) is a significant complication of spinal anesthesia. There is considerable variability in the incidence of PDPH, which is affected by a number of factors including age, gender, pregnancy, and needle type and size. ${ }^{1}$ Spinal needle damage has been mentioned in the literature in cases of difficult spinal block, but the problem of increased chances of PDPH even with a smaller gauge spinal needle with damaged tip has not been highlighted in the literature. Also, the increased chances of bleeding and consequent obstruction of the spinal needle by formation of blood clot can mimic a dry tap. This may prompt the operator to repeat efforts and thus increase the dural puncture attempts. We present a case which resulted in PDPH after spinal block with a deformed spinal needle due to calcified interspinous ligaments.

\section{Case report}

A 65 -year-old, $75 \mathrm{~kg}$ male was posted for emergency above knee amputation for wet gangrene of the right lower limb. Preanesthestic evaluation revealed normal hemogram, renal and liver function tests, and prothrombin time. However electrocardiogram (ECG) revealed poor progression of the R wave in the leads V1 to V5. Echocardiography revealed hypokinesia of the septum, anterior, and anterolateral wall. Left ventricular ejection fraction was $40 \%-45 \%$. Doppler of the right lower limb revealed arterial thrombosis with no flow in the popliteal artery or distal branches. Since it was an emergency surgery, the patient was immediately shifted into the operating room. ECG, pulse oximeter, and noninvasive blood pressure (NIBP) were attached. Arterial cannula in the left radial artery was secured under local anesthesia. Unilateral spinal anesthesia was planned. Under all aseptic precautions, a spinal block
Correspondence: Rakesh Garg

58-E Kavita Colony, Nangloi,

New Delhi-I I004I, India

Tel + 9l II 98I0394950

Fax

Email drrgarg@hotmail.com 
was attempted in the left lateral position by midline approach using a 25 G Quincke needle in the L3-4 interspace. Due to calcification of the ligaments, it was difficult to negotiate the needle and cerebrospinal fluid (CSF) could not be tapped in two attempts. The next attempt was made by a senior anesthesiologist who was able to feel the click of dural puncture after two more attempts. After removing the stylet, though the CSF was coming, flow was inadequate. Intrathecal administration of the drug was attempted, but could not be given successfully because of resistance. CSF flow was rechecked and again, flow was inadequate, but a small clot was visible near the hub coming out of the lumen of the spinal needle. With the help of the stylet, the clot was removed, after which free flow of the CSF could be observed and the drug could be administered successfully.

After removing the needle, we observed that the beveled tip of the spinal needle was bent. Adequate subarachnoid block was achieved and surgery completed uneventfully. On postoperative day one, the patient complained of headache, typically in the occipital region. Pain was managed conservatively with fluids and analgesics. The patient's headache gradually subsided by the fifth postoperative day and the patient was discharged on fourteenth day.

\section{Discussion}

Elderly patients may have calcified ligaments causing difficulty during insertion of a spinal needle. One option available in such cases is to use a larger gauge needle, but the chance of PDPH increases with this change. A paramedian approach may also be considered in such patients. In our case, although we used the $25 \mathrm{G}$ needle for spinal block, the patient still developed PDPH. Both needle diameter and its tip design have been considered as predictors of PDPH. ${ }^{2}$ Another possibility that we want to highlight is the presence of the bent beveled tip end of the spinal needle. In our case, during the multiple needle insertion attempts, the beveled end bent and as a result, when we were able to tap the CSF, the entry of the bent spinal needle tip may have made a larger hole or tear in the dura, resulting in PDPH. Moreover, during removal of the spinal needle another tear may have occurred in the dura as the needle was rotated to ensure a good flow of the CSF.

Contact with bone during insertion may lead to spinal needle tip deformation and these damaged needle tips could lead to an increase in the size of the subsequent dural tear. Recent in vivo studies have demonstrated that the cutting type spinal needle is more likely to be deformed after bony contact than comparably-sized pencil-point needles. ${ }^{1}$
However, no in vivo or in vitro work has yet demonstrated an increase in the size of dural perforation when damaged needles are used.

Our reason for believing this was a possibility in our case was the presence of a clot that came out through the spinal needle along with CSF. The likely etiology is that multiple attempts at spinal anesthesia traumatized the epidural vessels more so with the bent beveled end. The blood clot could have become entangled at the bent end and when the stylet was removed, the entangled clot at the tip came along with the CSF.

In one study, damage to the tips of Quincke type needles was studied using electron micrographs and around $15 \%$ of the needles were observed to be bent after performing a spinal block. ${ }^{3}$ A puncture with a bone contact was associated with evident tip damage in $7 \%$ of cases and holes made by needles exhibited an "open tin can" appearance. Similar observations of deformed tips in Whitacre spinal needles as well as cutbevel point needles were noted after microscopic examination and the author of one study believed that these microdeformations may be the cause of anatomical damage. ${ }^{4}$

We should be aware of even small resistance during spinal needle insertion because of the possibilities of severe deformation and injury of the anatomical structures or of dramatic in situ breakage of the spinal needle. We should also be vigilant with respect to bone contact of the spinal needle because damaged needle points can cause dural lacerations with subsequent cerebrospinal fluid leakage.

In a testing laboratory, the force necessary to bend 22- and 24-gauge Sprotte, 22- and 25-gauge Whitacre, and 22- and 25-gauge Quincke needles was measured using an Instron gauge (Instron Corp., Canton, MA) after microscopic verification of needle uniformity. ${ }^{5}$ The effects of lateral and axial forces were evaluated in separate experiments. The force needed to bend the Sprotte needles was less than that needed for the Whitacre and Quincke needles of similar size when lateral or axial pressure was applied. Examination of the needle tips demonstrated that the Sprotte needles were most likely to bend at the needle window, while the Quincke and Whitacre needles deformed at the point of clamping.

In our case, we failed to examine the needle tip between insertion attempts, which led to the postoperative PDPH. Also, the needle that we used did not have an introducer and therefore increased the chance of damage to the spinal needle. We suggest, in the elderly patient with possible ligament calcification, one should use an introducer needle to achieve the spinal block and in the case of multiple insertion attempts, the needle should be checked each time. Also, any 
change in the resistance from previous attempts or a gritting sensation during needle insertion should be taken seriously and the needle checked before further attempts are made.

\section{Disclosure}

The authors report no conflicts of interest in this work.

\section{References}

1. Turnbull DK, Shepherd DB. Postdural puncture headache: pathogenesis, prevention and treatment. Br J Anaesth. 2003;91:718-729.

2. Hafer J, Rupp D, Wollbruck M, Engel J, Hempelmann G. The effect of needle type and immobilization on postspinal headache. Anaesthetist. 1997;46:860-866.
3. Jokinen MJ, Pitkanen MT, Lehtonen E, Rosen Berg PH. Deformed spinal needle tips and associated dural perforations examined by scanning electron microscopy. Acta Anaesthesiol Scand. 1996;40:687-690.

4. Iannuzzi M, Voila G, Cerulli A, Chiefari M, Iannuzzi E. Deformation of the 27-gauge, 3.5 inch Whitacre spinal needle: macroscopic and microscopic findings. Minerva Anestesiol. 2007;73:525-527.

5. Lipov EG, Sosis MB, McCarthy RJ, Ivankovich AD. Does the design of the Sprotte spinal needle reduce the force needed to deform the tip? J Clin Anesth. 1994;6:411-413.

\section{Publish your work in this journal}

Local and Regional Anesthesia is an international, peer-reviewed, open access journal publishing on the development, pharmacology, delivery and targeting and clinical use of local and regional anesthetics and analgesics. The journal welcomes submitted papers covering original research, basic science, clinical studies, reviews \& evaluations,

\section{Dovepress}

guidelines, expert opinion and commentary, case reports and extended reports. The manuscript management system is completely online and includes a very quick and fair peer-review system, which is all easy to use. Visit http://www.dovepress.com/testimonials.php to read real quotes from published authors.

Submit your manuscript here: http://www.dovepress.com/local-and-regional-anesthesia-journal 